\title{
Does Mechanical Manipulation of the Reproductive Organs Cause a Prostaglandin Release in the Heifer During Embryo Transfer?
}

One of the problems encountered in embryo transfer (ET) in cattle is the wide variation in pregnancy rates. Many factors, of either embryonic, maternal or environmental origin, influence the result of the ET (Sreenan \& Diskin 1987). An important environmental factor is the method of transfer. Pregnancy rates are generally lower following non-surgical, compared with surgical transfer. In addition, the skill and experience of the operator is of great importance. Furthermore, pregnancy rates tend to decrease the longer the transfer catheter remains in the uterus (Rowe et al. 1980). One suggested reason for this is uterine trauma or irritation caused by the catheter with a subsequent endometrial inflammation. As the uterine environment is of great importance for the establishment of pregnancy, an inflammatory reaction would certainly diminish the chances for embryo survival. There is a possibility that the endometrium becomes damaged mechanically during the transfer procedure. This might be more pronounced in animals where ET is difficult to perform, due to anatomical reasons and/or, an inexperienced operator. Furthermore, when a longer time is needed for passing the cervix and placing the embryo in the tip of the uterine horn, the pregnancy rate seems to be influenced negatively.

Activation of the arachidonic acid cascade and formation of e.g. prostaglandins are parts of the inflammatory response (Weissmann et al. 1980). Prostaglandins can thus act as inflammatory mediators. Since prostaglandins have well-known effects on reproduction, such as luteolysis and abortion, they can cause reproductive disturbances.

The purpose of the present study was to examine if there was a prostaglandin mediated reaction in the uterus after a non-surgical ET, as reflected in increased prostaglandin metabolite levels in the general circulation.

Four heifers of the Swedish Friesian Breed (SLB) were used as recipients. The animals were synchronized with $500 \mu \mathrm{g}$ cloprostenol (Estrumat ${ }^{\circledR}$ vet., Pitman-Moore, Uxbridge, England) intramuscularly early in the luteal phase. On day $7 \pm 1$ in the oestrous cycle (day 0 = first day of standing heat), a simulated ET was performed according to our standard method (Greve 1981), including low epidural anaesthesia ( $5 \mathrm{ml}$ Xylocain, $20 \mathrm{mg} / \mathrm{ml}$, Astra, Södertälje, Sweden $)$. French straws $(0.25 \mathrm{ml})$ were loaded with phosphate buffered saline (PBS) supplemented with $1 \%$ foetal calf serum and kanamycin $(0.25 \mu \mathrm{g} / \mathrm{ml})$, and placed in a Cassou insemination gun (IMV, l'Aigle, France). The insemination gun was passed through the cervix into the horn ipsilateral to the corpus luteum. The tip of the gun was moved to the upper third of the uterine horn where the PBS was expelled. The transfer procedure was classified as easy, me- 


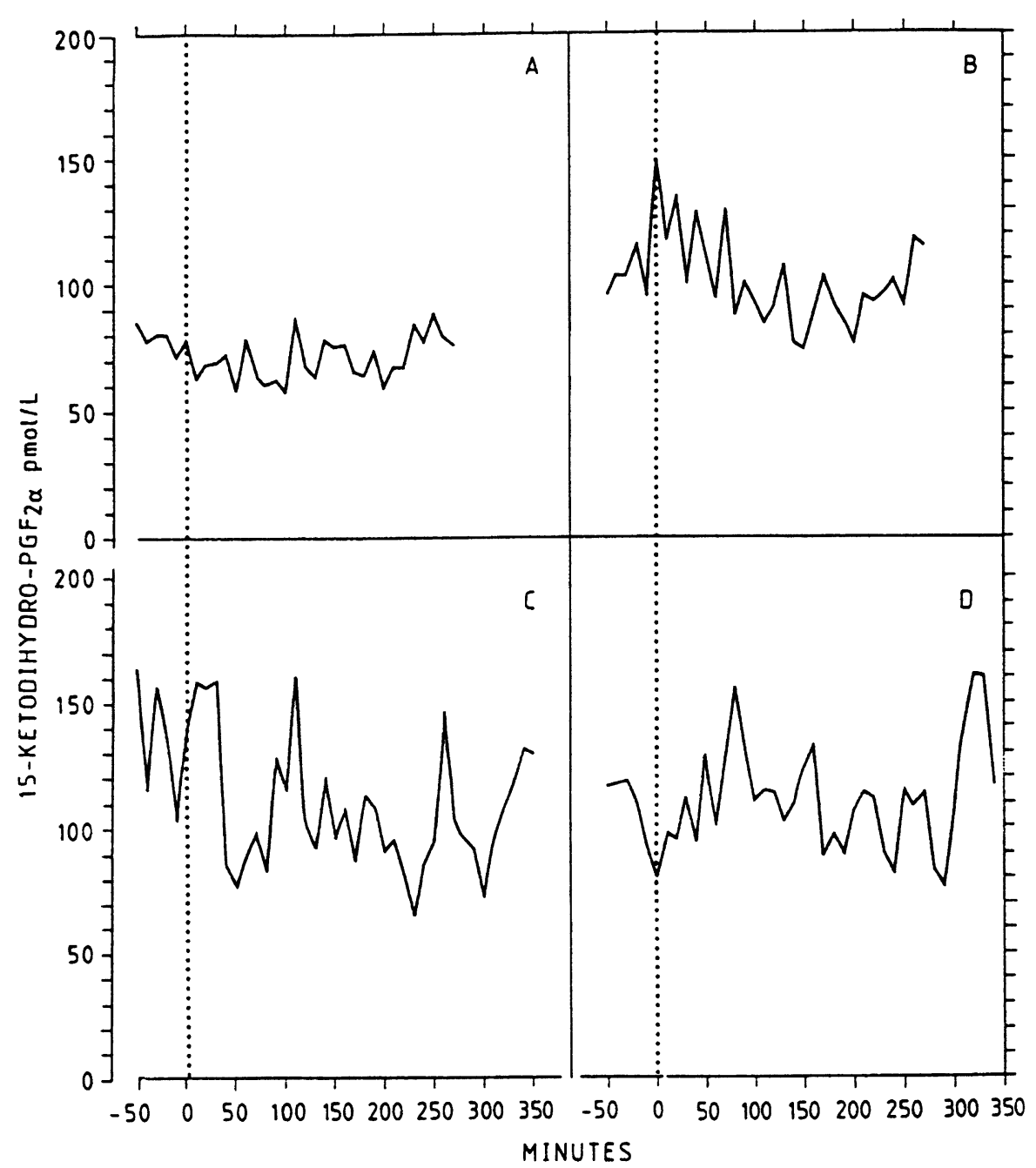

Figure 1. Levels of 15-ketodihydro-PGF $2 \mathrm{a}$ in the four heifers (A-D). Dotted vertical line indicates time for the ET procedure.

dium or difficult to perform, based on the difficulties of the manipulation and the time required to place the tip of the catheter in the desired position. To facilitate the blood sampling, a cannula was inserted into the jugular vein prior to the ET. Blood samples were withdrawn every $10 \mathrm{~min}$ beginning $50 \mathrm{~min}$ be- fore the ET and continuing for about $5 \mathrm{~h}$ (270$350 \mathrm{~min}$ ) after the ET. The samples were centrifuged immediately and the plasma frozen. The concentration of the main metabolite of prostaglandin (PG) $\mathrm{F}_{2 \alpha}$ was analysed by radioimmunoassay (Granström \& Kindahl 1982). 
The performance of the ET procedure in heifers A-D was classified as medium, easy, difficult and medium respectively. The procedure did not cause any significant changes in the $\mathrm{PGF}_{2 \alpha}$ metabolite pattern (Fig. 1). Furthermore, when the level of the $\mathrm{PGF}_{2 \alpha}$ metabolite was correlated with the ease of the transfer, no obvious correlation was seen. Even though the hormone patterns differ among the animals, all four are within the normal range at this stage of the oestrous cycle (e.g. Kindahl et al. 1976). A certain variation in basal levels is always seen during the cycle. A slight tendency of initially higher levels of the $\mathrm{PGF}_{2 \alpha}$ metabolite can be seen concomitantly and in conjunction with the manipulation in all heifers except one (heifer A). This might be a reflection of the handling of the heifer and the procedure of inserting the cannula, as well as the ET performance, including the low epidural anaesthesia.

The result of the present study suggests that a non-surgical ET procedure does not initiate a release of prostaglandins to a significant degree during the $1 \mathrm{st} \mathrm{h}$ after the manipulation.

\section{Acknowledgements}

The late Associate Professor Gunnar Fredriksson is acknowledged for valuable advice concerning the study. The authors wish to thank Dr. Martín Maciel for his support in the clinical work and Ms. Catharina Falkenberg for drawing the figure.

This study was supported by grants from the Swedish Council for Forestry and Agricultural Research.

\section{K. Odensvik, M. Duchens and H. Gustafsson}

Department of Obstetrics and Gynaecology, Faculty of Veterinary Medicine, Swedish University of Agricultural Sciences, Uppsala, Sweden

\section{References}

Granström E, Kindahl H: Radioimmunoassay of the major plasma metabolite of $\mathrm{PGF}_{2 \alpha}$, 15-keto13,14-dihydro-PGF ${ }_{2 \alpha}$. Methods Enzymol. 1982, $86,320-339$.

Greve T: Bovine egg transplantation in Denmark. Thesis, Royal Veterinary and Agricultural University, Copenhagen, Denmark, 1981.

Kindahl $H$, Edqvist L-E, Bane A, Granström E: Blood levels of progesterone and 15-keto-13,14dihydro-prostaglandin $F_{2 \alpha}$ during the normal oestrous cycle and early pregnancy in heifers. Acta endocr. 1976, 82, 134-149.

Rowe RF, Del Campo MR, Critser J K, Ginther OJ: Embryo transfer in cattle: Nonsurgical transfer. Amer. J. Vet. Res. 1980, 41, 1024-1028.

Sreenan JM, Diskin MG: Factors affecting pregnancy rate following embryo transfer in the cow. Theriogenology 1987, 27, 99-113.

Weissmann G, Smolen J, Korchak H: Prostaglandins and inflammation: Receptor/Cyclase coupling as an explanation of why PGEs and $\mathrm{PGI}_{2}$ inhibit functions of inflammatory cells. Adv. Prostaglandin Thromboxane Research, Vol 8, Raven Press, New York, 1980, 1637-1653.

(Received April 26, 1993; accepted May 18, 1993).

Reprints may be requested from: K. Odensvik, Department of Obstetrics and Gynaecology, Faculty of Veterinary Medicine, Swedish University of Agricultural Sciences, S-750 07 Uppsala, Sweden. 